\title{
Nitrogenation and Hot Embrittlement in Ti-added Ultra Low Carbon Steels
}

\author{
Yasuhiro MAEHARA and Kazuhito KAMEI
}

Research and Development Center, Sumitomo Metal Industries Limited, Fuso-cho, Amagasaki, Hyogo-ken, 660 Japan.

(Received on May 27, 1994; accepted in final form on July 15, 1994)

\begin{abstract}
Hot ductility of Ti-added ultra low carbon steels has been studied with particular emphasis on the bahavior of TiS. Hot ductility of low Mn low carbon steels initially solution-treated in the high temperature $y$ region is reduced with intergranular fracture by high strain rate deformation at temperatures ranging from 900 to $1100^{\circ} \mathrm{C}$. This can be explained by the fact that hardening due to dynamic precipitation of Fe-rich sulfide within the matrix accelerates the void initiation at interface of grain boundary precipitate/matrix. In Ti-added steels, the ductility loss is considerably smaller compared to that of Ti-free low Mn steels, since Ti has a role of trapping $\mathrm{S}$ atoms as TiS particles in the same way as $\mathrm{Mn}$. However, nitrogenation due to heating in the nitrogen gas atmosphere or in air changes TiS into the more stable TiN especially in the surface layer. As a result, the extra free $S$ atoms formed by this reaction leads to hot embrittlement by the same mechanism.
\end{abstract}

KEY WORDS: ultra low carbon steels; nitrogenation; hot embrittlement; titanium sulfide; titanium nitride.

\section{Introduction}

Hot embrittlement due to sulfur in low carbon low alloy steels has been extensively studied in relation to the over heating phenomena. ${ }^{1-16)}$ The hot ductility of the specimens on the way of cooling from remelting or high temperature solution treatment is largely reduced with austenite intergranular fracture by high strain rate deformation at temperatures ranging from 800 to $1100^{\circ} \mathrm{C}$. In each steel, when the specimens are heated above a critical temperature, marked embrittlement is observed. In this meaning, this embrittlement is called "over heating", and closely related to cracking in the hot rolling process or in the heat affected zone after welding. The critical heating temperature introducing the embrittlement is determined by the contents of $\mathrm{S}$ and $\mathrm{Mn}$, which can trap $\mathrm{S}$ atoms as coarse $\mathrm{MnS}$ particle. ${ }^{15}$ ) Therefore the critical temperature is raised by increasing the content ratio of $\mathrm{Mn} / \mathrm{S}$. That is, the embrittlement occurs by the existence of free $\mathrm{S}$ atoms, which is formed by the resolution of $\mathrm{MnS}$ precipitates in the initial heating process. The free $\mathrm{S}$ atoms can precipitate dynamically during the subsequent hot deformation as Fe-rich sulfides in the austenite grains, leading to precipitation hardening. ${ }^{16)}$ As a result, strain concentrates within soft precipitation free zones along the grain boundaries. Microvoids formed by the decohesion of coarser grain boundary sulfides from the matrix coalesce into final ductile intergranular fracture. Therefore the hot embrittlement is largely suppressed by slow cooling to the deformation temperature, isothermal holding before deformation or by slow strain rate deformation, since the dynamic precipitation of fine Fe-rich sulfide can largely be suppressed by the forming of coarse MnS precipitates prior to or in the early stage of deformation. ${ }^{13,16)}$

Recently, interstitial free (IF) steel sheets, in which the interstitial atoms of $\mathrm{C}$ and $\mathrm{N}$ are trapped by small amounts of $\mathrm{Ti}$ addition as $\mathrm{TiC}$ and/or $\mathrm{TiN}$, have been increasingly adopted especially for automobile panel purpose because of their excellent deep drawability. Another role of Ti addition in this kind of steel is to trap $\mathrm{S}$ atoms as coarse TiS particles, whose role is similar to that of $\mathrm{Mn}$ in high temperature region. In the hot working process in air, however, nitrogenation can occur significantly, resulting in the change of precipitates from TiS to the thermodynamically more stable TiN. Extra free $S$ atoms formed by the reaction may introduce hot embrittlement by the same mechanism. However, there have been no reports on the hot embrittlement of this kind of steel. The objective of this study is to clarify the possibility of the hot embrittlement of Ti-added IF steels with particular emphasis on the behavior of TiS.

\section{Experimental Procedure}

Six kinds of Ti-added ultra low carbon steels with different $\mathrm{Mn}$ contents were prepared by a laboratory induction furnace as $20 \mathrm{~kg}$ ingots. The chemical compositions are given in Table 1. They were hot-forged and rolled into $15 \mathrm{~mm}$ diameter bars. From these bars cylindrical tensile specimens were machined in the rolling direction. The gage length, gage diameter and fillet radius were 8,6 and $5 \mathrm{~mm}$, respectively. The specimens were heated at given temperatures from 1100 to $1350^{\circ} \mathrm{C}$ in an infrared image furnace attached to the instron-type 
Table 1. Chemical composition of the steels used. (wt \%)

\begin{tabular}{lcccccccc}
\hline Steel & C & Si & Mn & P & S & Al & N & Ti \\
\hline M1 & 0.003 & 0.001 & 0.250 & 0.010 & 0.005 & 0.077 & 0.0040 & 0.053 \\
M2 & 0.003 & 0.002 & 0.200 & 0.010 & 0.005 & 0.073 & 0.0037 & 0.054 \\
M3 & 0.003 & 0.002 & 0.150 & 0.010 & 0.005 & 0.069 & 0.0035 & 0.054 \\
M4 & 0.003 & 0.002 & 0.096 & 0.009 & 0.005 & 0.058 & 0.0032 & 0.053 \\
M5 & 0.004 & 0.001 & 0.057 & 0.008 & 0.005 & 0.058 & 0.0027 & 0.052 \\
M6 & 0.003 & 0.001 & 0.005 & 0.010 & 0.005 & 0.056 & 0.0027 & 0.056 \\
\hline
\end{tabular}

tensile testing machine. After keeping for $10 \mathrm{~min}$, they were cooled to deformation temperatures ranging from 700 to $1300^{\circ} \mathrm{C}$, held for $1 \mathrm{~min}$ just for temperature homogenization, and then isothermally pulled to failure at constant cross head speeds from 1 to $500 \mathrm{~mm} / \mathrm{min}$ (the initial strain rate ranges from $2 \times 10^{-3}$ to $2 \mathrm{~s}^{-1}$ ). Although most of the hot tensile tests were conducted in a flowing Ar gas atmosphere to prevent oxidization, in some cases nitrogen gas atmosphere was employed in order to investigate the effect of surface nitrogenation on the tensile properties.

On these speciments, metallographic and fractographic examinations were conducted by means of transmission electron and scanning electron microscopy.

\section{Experimental Results}

\subsection{Tensile Properties}

Figure 1 shows tensile properties as a function of the deformation temperature in the base Steel M3, which was deformed at a strain rate of $1.04 \mathrm{~s}^{-1}$ after solution-treated at $1300^{\circ} \mathrm{C}$ for $10 \mathrm{~min}$ in an $\mathrm{Ar}$ gas atmosphere. The ductility evaluated by reduction in area $(R A)$ shows a trough at temperatures from 900 to $1050^{\circ} \mathrm{C}$. However, it can be seen from the comparison with the results of conventional Ti-free steels ${ }^{13,16)}$ that the ductility loss of this kind IF steel is fairly small. That is, in case of Ti-free steels the $R A$ in the trough temperature region reaches very small values less than $20 \%,{ }^{16)}$ in keeping with the fact that the critical $\mathrm{Mn}$ content in Ti-added IF steels is considerably smaller than that of conventional Ti-free steels. In Fig. 1, the flow stress increases gradually with decreasing the deformation temperature above $900^{\circ} \mathrm{C}$. Large stress drop around $850^{\circ} \mathrm{C}$ corresponds to the phase transformation from austenite to ferrite. Figure 2 shows effects of the solution treatment temperature and atmosphere on tensile properties of Steel M3 deformed at $1000^{\circ} \mathrm{C}$ and at a strain rate of $1.04 \mathrm{~s}^{-1}$. In case of a flowing Ar gas atmosphere, the ductility loss is observed only when the heating temperature is above $1300^{\circ} \mathrm{C}$, and the ductility is rapidly improved by lowering the heating temperature. While, in the case of testing in the nitrogen gas atmosphere, the critical heating temperature giving the ductility loss is significantly lower than that tested in the Ar gas atmosphere, and the large ductility loss is observed even after heating at $1250^{\circ} \mathrm{C}$. Figure 3 shows the effect of $\mathrm{Mn}$ content on tensile properties when the specimens were deformed at $1000^{\circ} \mathrm{C}$ at a strain rate of $1.04 \mathrm{~s}^{-1}$ after heating at $1250^{\circ} \mathrm{C}$ for $30 \mathrm{~min}$ or at $1300^{\circ} \mathrm{C}$ for $60 \mathrm{~min}$ in flowing $\mathrm{Ar}$

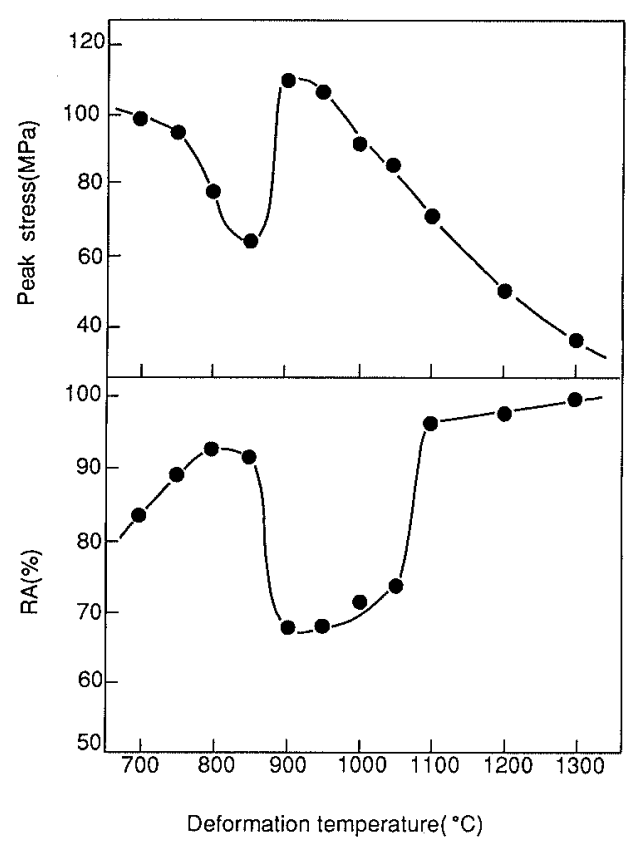

Fig. 1. Variation of tensile properties with deformation temperature in the base Steel M3; the specimens were solution-treated at $1300^{\circ} \mathrm{C}$ for $10 \mathrm{~min}$ and deformed at a strain rate of $1.04 \mathrm{~s}^{-1}$ in air.

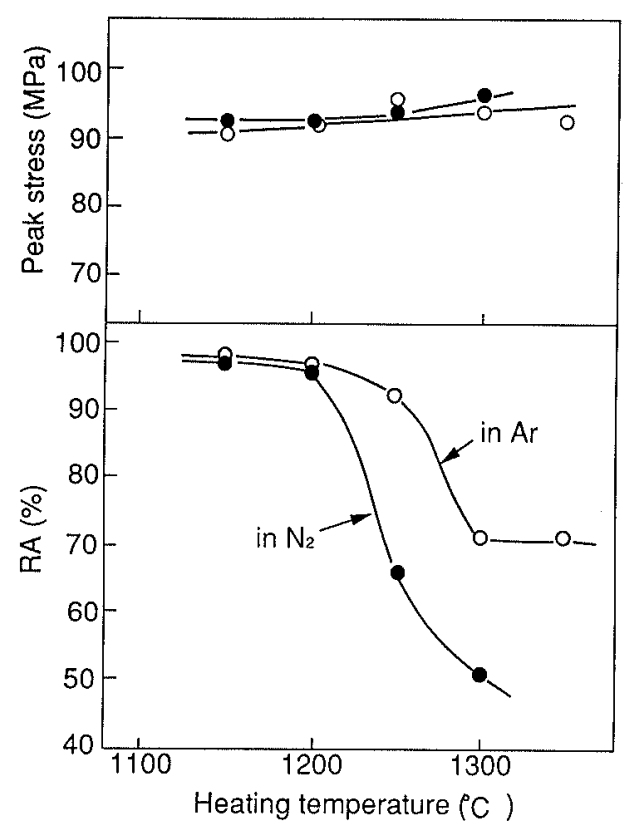

Fig. 2. Effect of solution treatment (heating) temperature on tensile properties in the base Steel M3; the specimens were deformed at $1000^{\circ} \mathrm{C}$ at a strain rate of $1.04 \mathrm{~s}^{-1}$ after solution-treated for $30 \mathrm{~min}$ at various temperatures. 
or nitrogen gas atmosphere. In case of $1250^{\circ} \mathrm{C}$ heating for $30 \mathrm{~min}$, all the specimens heated in Ar show fairly good ductility, and the steels with smaller amount of Mn than $0.15 \%$ show slight ductility loss. When the specimens were heated at $1300^{\circ} \mathrm{C}$ for $60 \mathrm{~min}$, a ductility trough was observed even in Ar gas atmosphere, and large ductility loss was observed in nitrogen gas atmosphere especially in low Mn steels.

Figure 4 shows effect of the heating time and the atmosphere on the ductility of Steel M5. The specimens were heated at $1350^{\circ} \mathrm{C}$, and deformed at $1000^{\circ} \mathrm{C}$ at a

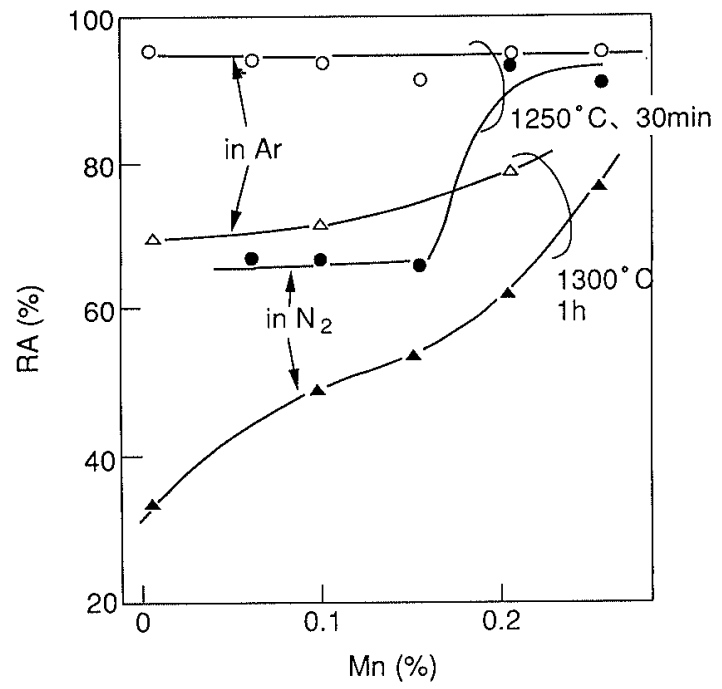

Fig. 3. Effects of $\mathrm{Mn}$ content and initial solution treatment conditions on the ductility at $1000^{\circ} \mathrm{C}$ at a strain rate of $1.04 \mathrm{~s}^{-1}$.
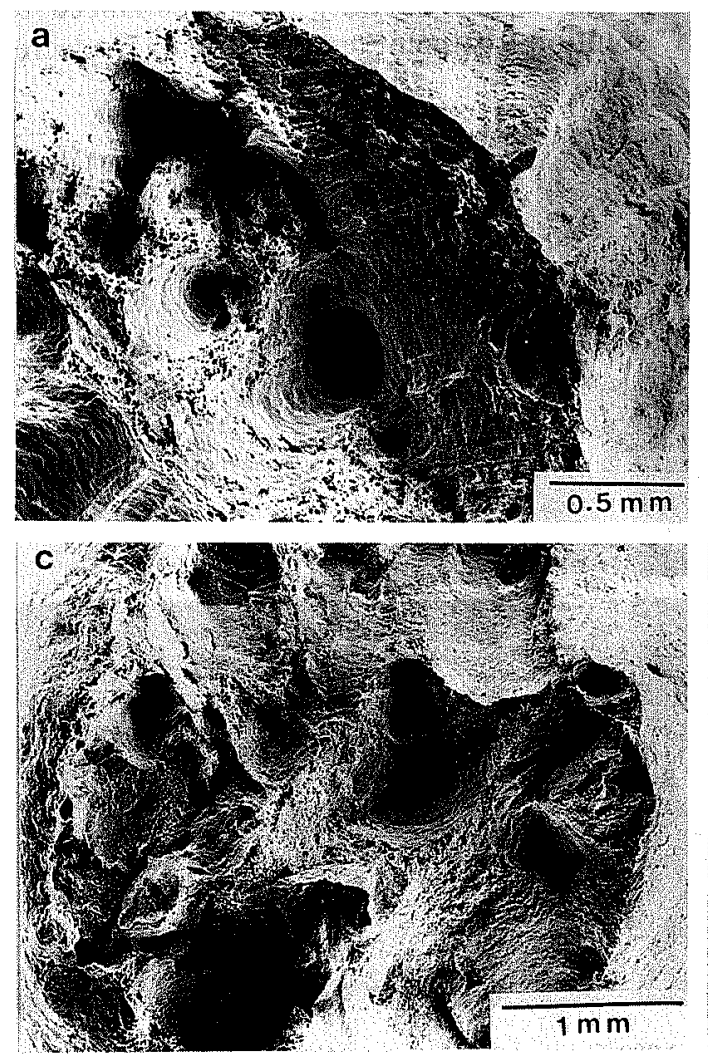

strain rate of $2 \mathrm{~s}^{-1}$. Although the ductility was not affected by heating for long time in Ar gas atomosphere, that was considerably reduced by heating in nitrogen atmosphere.

\subsection{Fractography}

Figure 5 shows effect of atmosphere on the fracture surface of Steel M3 specimens deformed at $1000^{\circ} \mathrm{C}$ at a strain rate of $1.04 \mathrm{~s}^{-1}$ after heating at $1250^{\circ} \mathrm{C}$ for $60 \mathrm{~min}$. When deformed in an Ar gas atmosphere, the fracture mode was transgranular ductile of Chisel point type. By heating in nitrogen gas the fracture mode changed

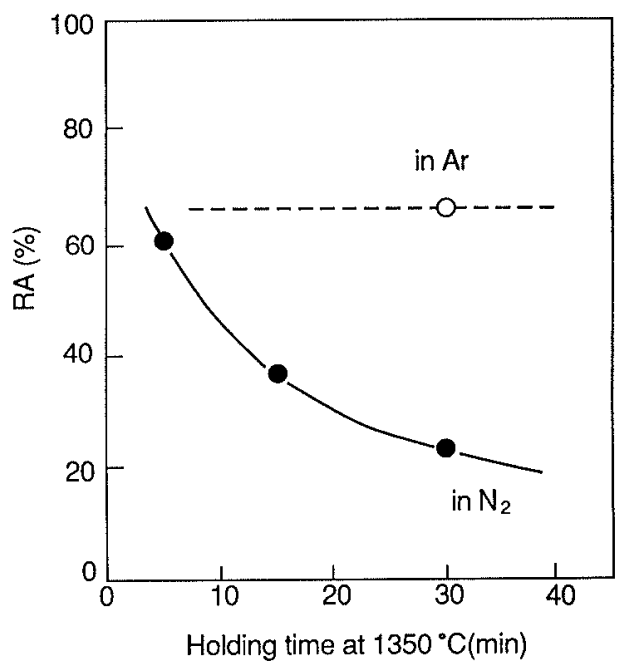

Fig. 4. Effects of holding time and atmosphere when heating at $1350^{\circ} \mathrm{C}$ on the ductility at a strain rate of $2 \mathrm{~s}^{-1}$ of Steel M5.
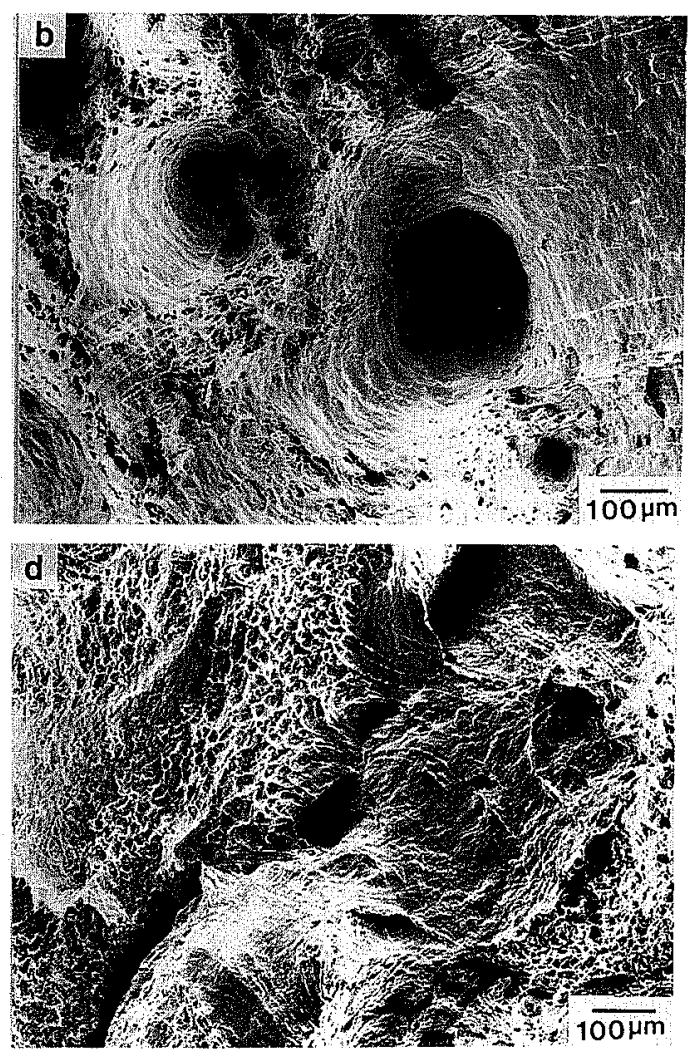

Fig. 5. Effect of solution treatment temperature on the fracture surface of Steel $\mathrm{M} 3$ deformed at $1000^{\circ} \mathrm{C}$ at a strain rate of $1.04 \mathrm{~s}^{-1}$; the solution treatment conditions are (a), (b) $1250^{\circ} \mathrm{C}$ for $30 \mathrm{~min}$ in $\mathrm{Ar}$ and (c), (d) $1250^{\circ} \mathrm{C}$ for $60 \mathrm{~min}$ in $\mathrm{N}_{2}$. 
significantly into intergranular. The detailed examination revealed that there were shallow dimples on the intergranular facets, as in Fig. 5(d). Figure 6 shows the fracture surface of Steel M6 specimen deformed at $1000^{\circ} \mathrm{C}$ at a strain rate of $1.04 \mathrm{~s}^{-1}$ after heating at $1300^{\circ} \mathrm{C}$ for $60 \mathrm{~min}$ in nitrogen, showing a typical intergranular
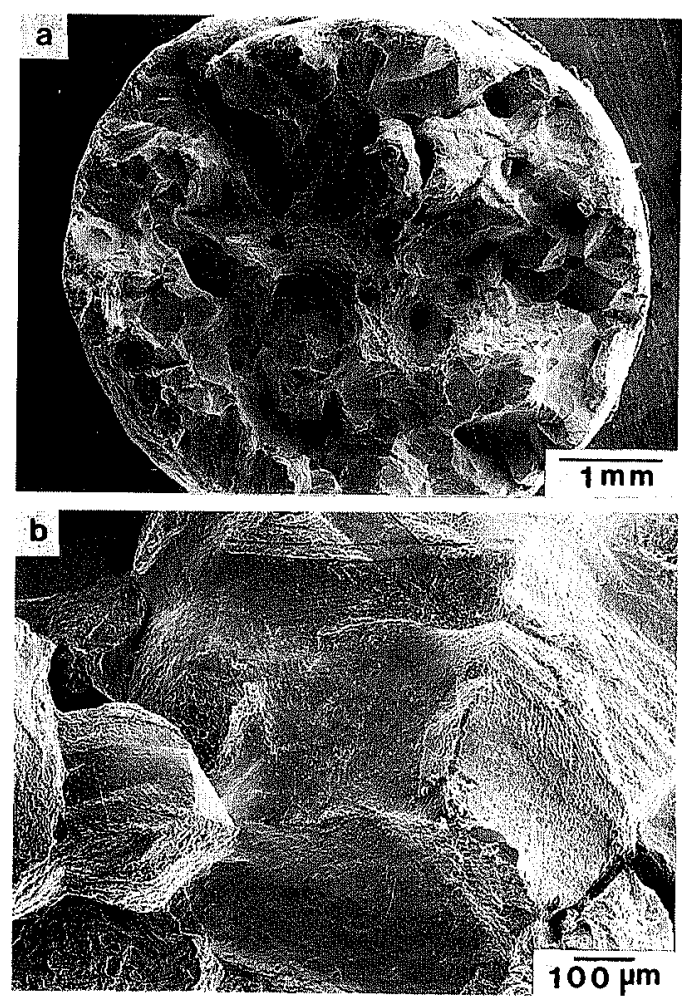

Fig. 6. Fracture surface of Steel M6 specimen deformed at a strain rate of $1.04 \mathrm{~s}^{-1}$ after solution-treated at $1300^{\circ} \mathrm{C}$ for $60 \mathrm{~min}$ in nitrogen gas atmosphere. fracture mode. Figure 7 shows the fracture surface of Steel M3 specimen deformed at $1000^{\circ} \mathrm{C}$ after heating at $1250^{\circ} \mathrm{C}$ for $30 \mathrm{~min}$ in nitrogen. The center area shows ductile, while the area in the vicinity of the specimen surface shows brittle intergranular failure.

Figure 8 shows depth of austenite intergranular fracture region as a function of holding time at $1350^{\circ} \mathrm{C}$ to Steel M5. The specimens were heated in nitrogen gas atmosphere, and deformed at $1000^{\circ} \mathrm{C}$ at a strain rate of $2 \mathrm{~s}^{-1}$. The depth increased with increasing the holding time.

\subsection{Metallography}

The constituent of the precipitates after the hot tensile deformation depends largely on the atmosphere. Figure 9 shows the effect of atmosphere on the precipitation behavior of the high Mn Steel M1. The specimens were deformed at $1000^{\circ} \mathrm{C}$ after heating at $1300^{\circ} \mathrm{C}$ for $60 \mathrm{~min}$. When tested in an Ar gas atmosphere, coarse TiS and MnS precipitates dispersed as in Fig. 9(b). On the contrary, when tested in a nitrogen gas atmosphere, very coarse TiN precipitates were observed in addition to coarse $\mathrm{MnS}$ as in Fig. 9(a). Besides it should be noted that very fine particles dispersed. These are interpreted as Fe-rich sulfide formed dynamically during the high strain rate deformation. ${ }^{16)}$

\section{Discussion}

Titanium-added ultra low carbon steel shows ductility trough around 900 to $1050^{\circ} \mathrm{C}$ with intergranular fracture of austenite, when deformed at high strain rate after solution treatment in high temperature austenite region (Fig. 1). The ductility loss is enhanced by raising the solution treatment temperature or by decreasing the $\mathrm{Mn}$

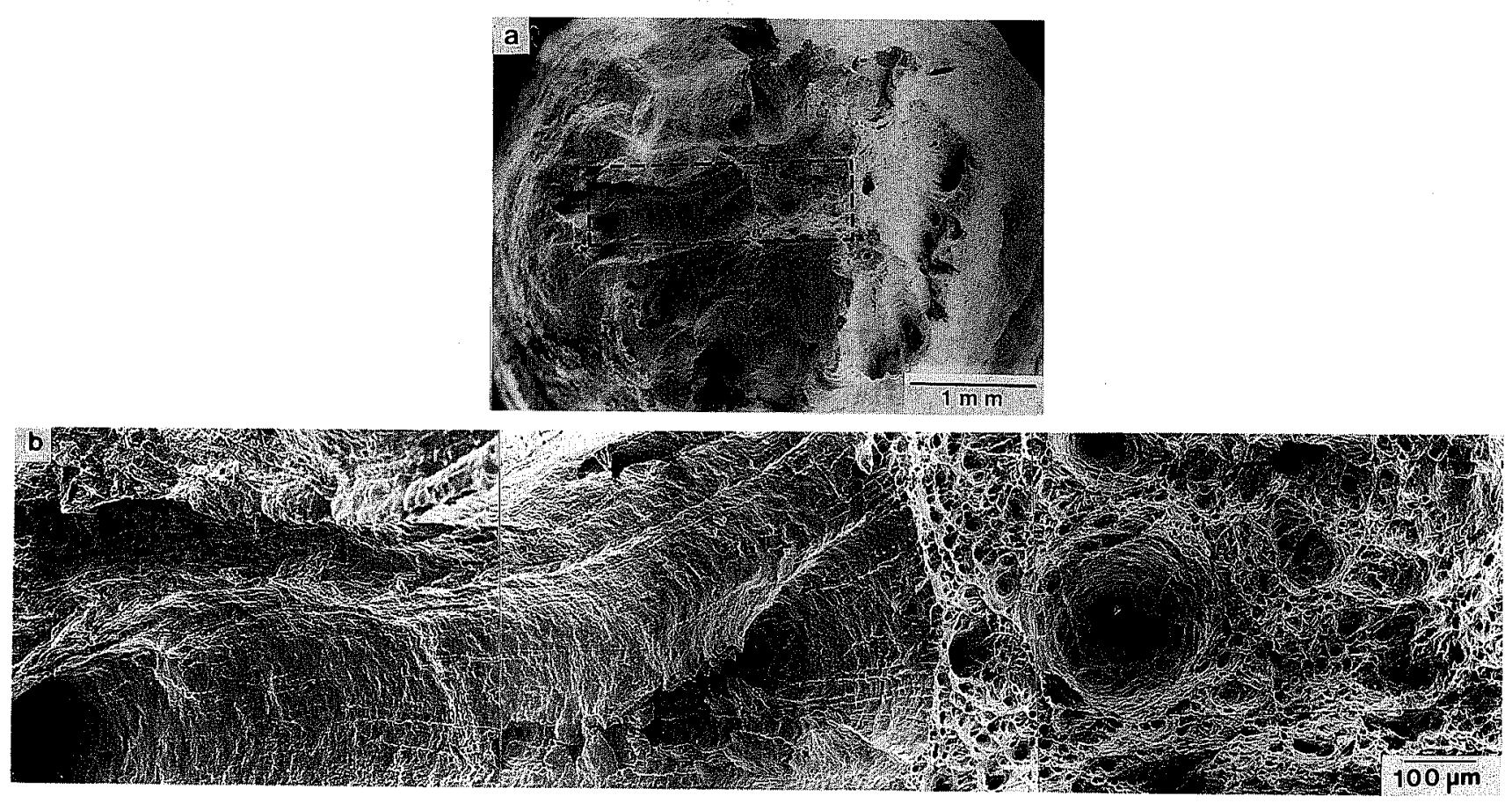

Fig. 7. Fracture surface of Steel M3 specimen deformed at $1000^{\circ} \mathrm{C}$ at a strain rate of $1.04 \mathrm{~s}^{-1}$ after solution-treated at $1250^{\circ} \mathrm{C}$ for $30 \mathrm{~min}$ in nitrogen gas atmosphere. (b) is higher magnification of the area surrounded by broken line in (a). Note different fracture modes; transgranular ductile in the center portion and intergranular in the surface layer. 


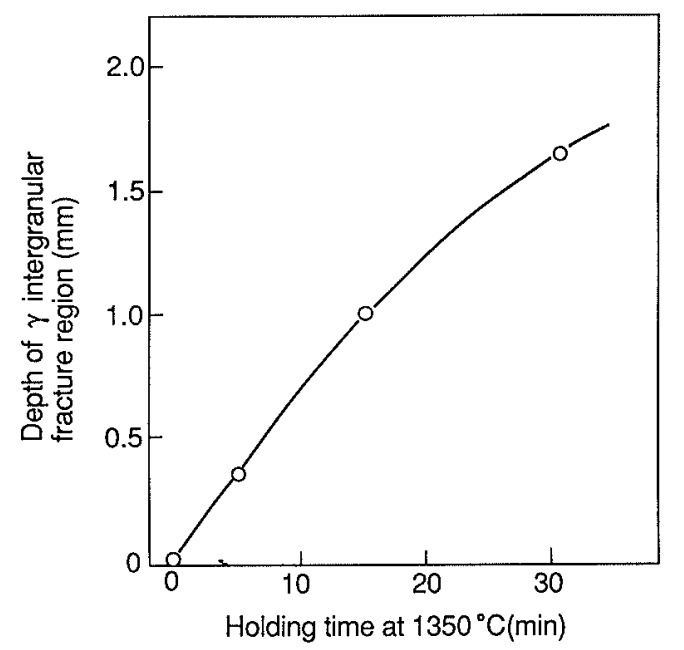

Fig. 8. Depth of austenite intergranular fracture region of the Steel M5 specimens deformed at $1000^{\circ} \mathrm{C}$ at a strain rate of $1.04 \mathrm{~s}^{-1}$ as a function of holding time at the initial solution treatment temperature of $1350^{\circ} \mathrm{C}$ in nitrogen.
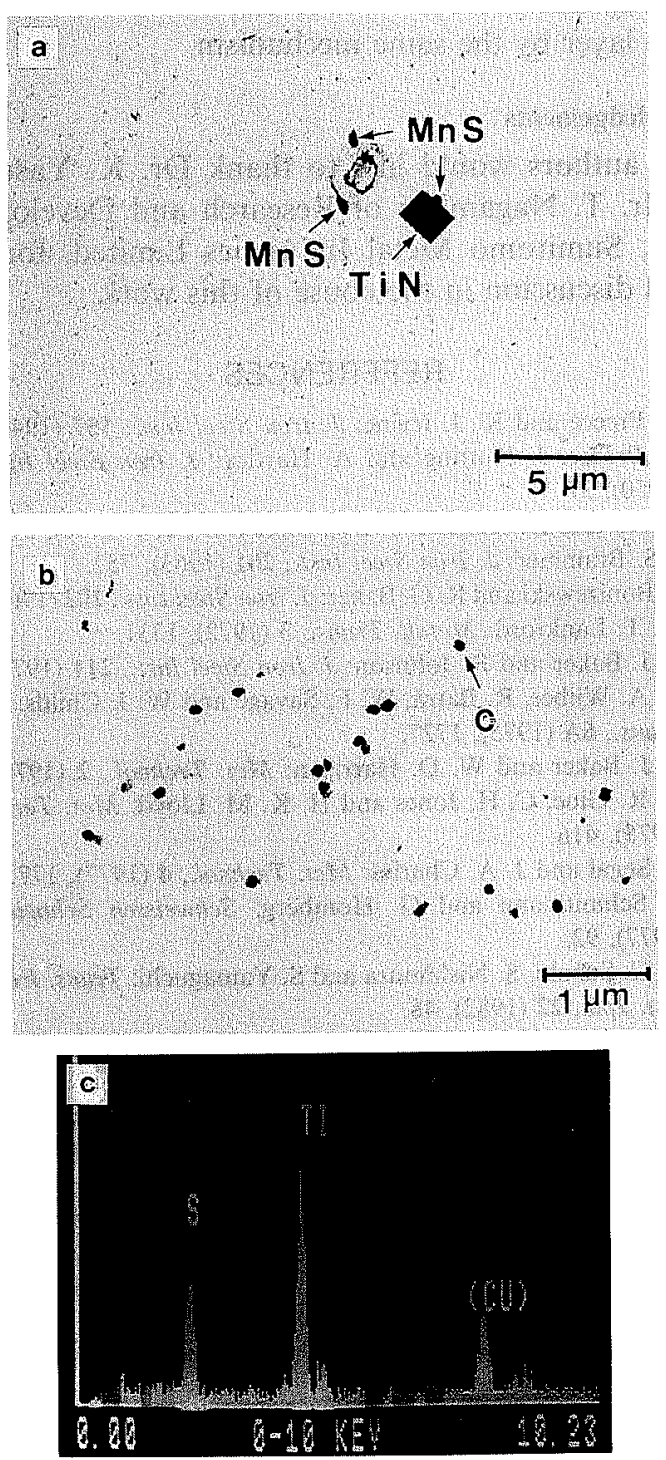

Fig. 9. TEM micrographs of the replicas extracted from Steel Ml specimen deformed at $1000^{\circ} \mathrm{C}$ at a strain rate of $1.04 \mathrm{~s}^{-1}$ after solution-treated at $1300^{\circ} \mathrm{C}$ for $60 \mathrm{~min}$ in (a) $\mathrm{N}_{2}$ and (b) Ar atmospheres, respectively. (c) is EDX spectrum of the precipitate indicated by an arrow in (b), showing TiS. content. This phenomenon is so called "over heating", which is common in low Mn Al-killed steels. The different point is that the ductility loss in the Ti-added ultra low C steel is marked when tested in a nitrogen gas atmosphere. The cause of this difference will be discussed here.

If $\mathrm{S}$ atoms are fixed by $\mathrm{Mn}$ and $\mathrm{Ti}$ as coarse $\mathrm{MnS}$ and TiS precipitates, the specimens do not show the ductility loss. When the specimens are heated in a nitrogen gas atmosphere, the $\mathrm{N}$ atoms can enter into the specimen through the specimen surface. The formation free energy gap $^{18)}$ between TiN and TiS will change TiS into TiN. This change can also be expected from the comparison between following two solubility product equations ${ }^{19}$;

$$
\begin{aligned}
& \log [\mathrm{Ti}][\mathrm{S}]=-17640 / T+8.20 \\
& \log [\mathrm{Ti}][\mathrm{N}]=-15020 / T+3.82
\end{aligned}
$$

As a result, the TiS particles will change into thermodynamically more stable TiN as follows;

$$
\mathrm{TiS}+\frac{1}{2} \mathrm{~N}_{2} \rightarrow \mathrm{TiN}+\mathrm{S}
$$

In fact, in the specimen heated at $1300^{\circ} \mathrm{C}$ for $60 \mathrm{~min}$ in the nitrogen gas atmosphere, coarse TiN particles were

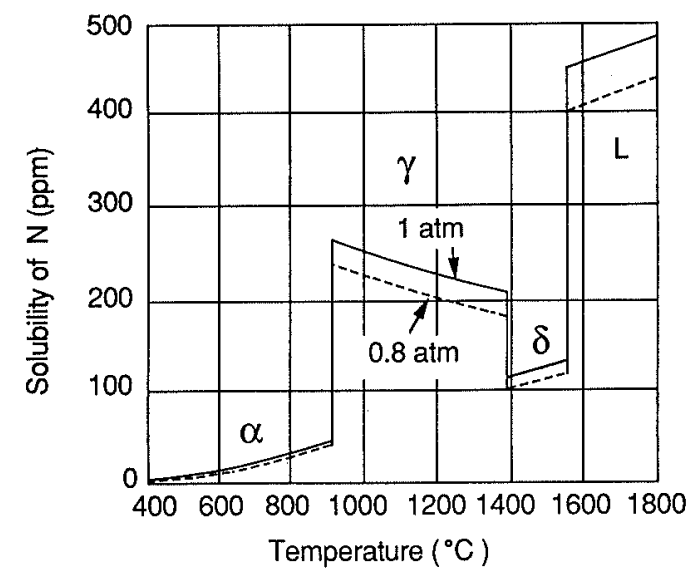

Fig. 10. Solubility of nitrogen in pure $\mathrm{Fe}$ as a function of temperature under $1 \mathrm{~atm} \mathrm{~N}_{2}$ atmosphere. ${ }^{17)}$ The data under $0.8 \mathrm{~atm} \mathrm{~N}_{2}$ atmosphere, which corresponds to that in $1 \mathrm{~atm}$ air, was calculated using Sieverts' law.

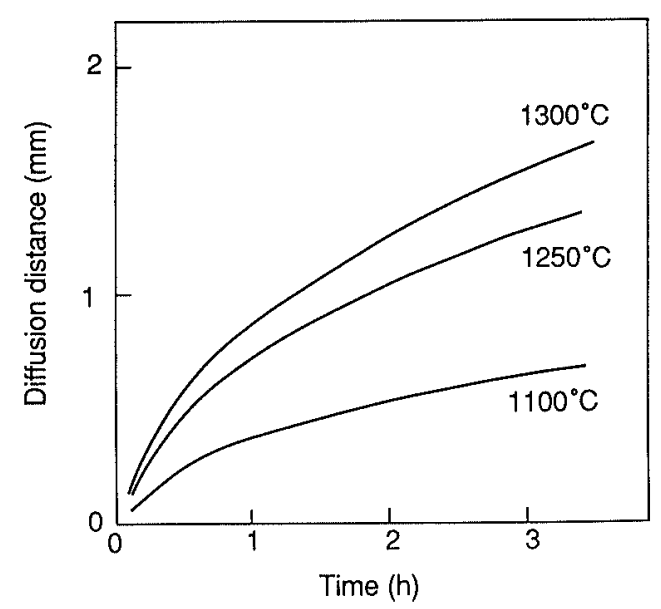

Fig. 11. Diffusion distance of nitrogen in the austenite $v s$. time at various temperatures. 


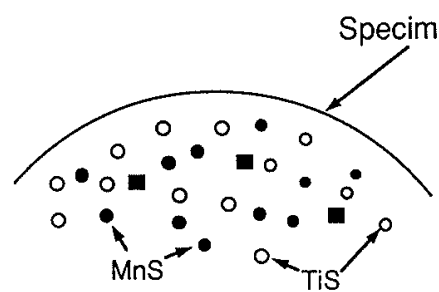

(a) in $\operatorname{Ar}$ gas

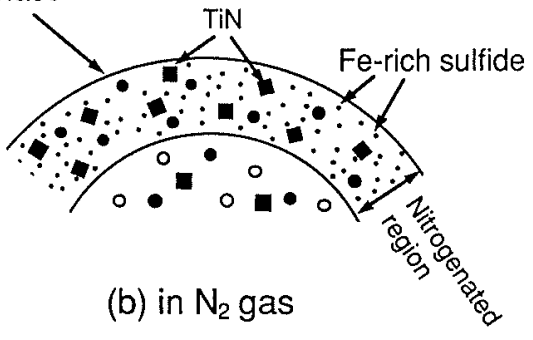

Fig. 12.

Schematic illustrations showing sulfide and nitride precipitates on the transverse cross section of cylindrical tensile specimens, which were deformed at a high strain rate around $1000^{\circ} \mathrm{C}$ after solution treatment in (a) $\mathrm{Ar}$ gas and (b) $\mathrm{N}_{2}$ gas atmospheres. observed instead of TiS (Fig. 9). Fine precipitates in Fig. 9(a) can be interpreted as Fe-rich sulfides formed dynamically during the high strain rate deformation. They can strengthen the matrix by the precipitation hardening. ${ }^{16)}$ Strain concentration within soft precipitation free zones along the grain boundaries initiates decohesion of the grain boundary precipitates/matrix interfaces, leading to the ductile intergranular fracture of austenite.

Next, the degree of nitrogenation will be estimated on the base of thermodynamical data. ${ }^{17)}$ Figure 10 shows the solubility of nitrogen in iron as a function of temperature under 1 and 0.8 atm nitrogen, which approximately corresponds to air. It can be seen that the solubility limit of nitrogen reaches almost $200 \mathrm{ppm}$ at $1300^{\circ} \mathrm{C}$. Figure 11 shows diffusion distance of nitrogen in $\gamma-\mathrm{Fe}$ vs. time at various temperatures. When the specimen is heated in nitrogen atmosphere at $1300^{\circ} \mathrm{C}$ for $1 \mathrm{~h}$, the $\mathrm{N}$ content in the portion $1 \mathrm{~mm}$ inner from the surface can be $60-70 \mathrm{ppm}$, which is $30-40 \mathrm{ppm}$ higher value than that before nitrogenation. This means that the above reaction described by Eq. (1) can occur significantly even in the center portion of $6 \mathrm{~mm}$ diameter specimen. In fact, austenite intergranular embrittlement occurred even in the center portion by the subsequent high strain rate deformation (Fig. 6). When the specimen is heated at $1250^{\circ} \mathrm{C}$ for $30 \mathrm{~min}$, the above reaction can be restricted to the surface layer, in keeping with the fractographic observation after the subsequent deformation (Fig. 7).

The precipitates of nitrides and sulfides in the deformed tensile specimens after heated in $\mathrm{Ar}$ and $\mathrm{N}_{2}$ atmosphere can be depicted as in Figs. 12(a) and 12(b), respectively.

\section{Conclusions}

Hot ductility of Ti-added ultra low carbon steels has been studied with particular emphasis on the behavior of TiS, and following results were obtained.

(1) Hot ductility of Ti-added ultra low carbon steels, which are initially solution-treated in high temperature $\gamma$ region, is decreased with intergranular fracture by high strain rate deformation at temperatures ranging from 900 to $1100^{\circ} \mathrm{C}$. This can be explained by that hardening due to dynamic precipitation of Fe-rich sulfide within the matrix introduces the void initiation at interface of grain boundary precipitate/matrix.

(2) In Ti-added steels, the ductility loss is considerably small compared with that of Ti-free low Mn steels, since Ti has a role of trapping $\mathrm{S}$ atoms as TiS in the same way of $\mathrm{Mn}$. However, nitrogenation due to heating in the nitrogen gas atmosphere or in air changes TiS to thermodynamically more stable TiN especially in the surface layer. As a result, the extra free $S$ atoms formed by this reaction leads to hot embrittlement in the surface layer by the same mechanism.

\section{Acknowledgements}

The authors would like to thank Dr. K. Yasumoto and Mr. T. Nagamichi of Research and Development Center, Sumitomo Metal Industries Limited, for their helpful discussion in the couse of this work.

\section{REFERENCES}

1) A. Preece and K. J. Irvine: J. Iron Steel Inst., 157 (1947), 336.

2) A. Preece, J. Nutting and A. Hartley: J. Iron Steel Inst., 164 (1950), 37

3) T. Ko and D. Hanson: J. Iron Steel Inst., 164 (1950), 51.

4) I. S. Brammer: J. Iron Steel Inst., 201 (1963), 752.

5) T. Bonizewski and R. G. Baker: J. Iron Steel Inst., 202 (1964), 921.

6) W. T. Lankford: Metall. Trans., 3 (1972), 1331.

7) T. J. Baker and R. Johnson: J. Iron Steel Inst., 211 (1973), 783.

8) G. A. Wilber, R. Batra, W. F. Savage and W. J. Childs: Metall. Trans., 6A (1975), 1727.

9) T. J. Baker and W. D. Harrison: Met. Technol., 2 (1975), 201.

10) D. R. Glue, C. H. Jones and H. K. M. Lloyd: Met. Technol., 2 (1975), 416.

11) A. Segal and J. A. Charles: Met. Technol., 4 (1977), 177

12) E. Schmitmann and G. Homberg: Schweissen Schneiden, 29 (1977), 92.

13) H. G. Suzuki, S. Nishimura and S. Yamaguchi: Trans. Iron Steel Inst. Jpn., 22 (1982), 48.

14) D. J. Allen and D. W. Wolsterholme: Met. Technol., 9(1982), 266.

15) N. P. McLeod and J. Nutting: Met. Technol., 9 (1982), 399.

16) K. Yasumoto, Y. Maehara, S. Ura and Y. Ohmori: Mater. Sci. Technol., 1 (1985), 111.

17) Appropriate equilibrium constant in steel making reaction (in Japanese), ed. by Comm. of Japan Soc. for Promotion of Sci. Tokyo, (1984), 28.

18) J. F. Elliott and M. Gleiser: Thermochemistry for Steel Making Vol. 1, Addison Wesley, NY, (1960).

19) W. J. Liu, S. Yue and J. J. Jonas: Metall. Trans., 20A (1989), 1907. 